\title{
The relationship between cellular adhesion and surface roughness for polyurethane modified by microwave plasma radiation
}

This article was published in the following Dove Press journal:

International Journal of Nanomedicine

6 April 2011

Number of times this article has been viewed

\author{
Saeed Heidari Keshel' \\ S Neda Kh Azhdadi ${ }^{2}$ \\ Azadeh Asefnezhad ${ }^{2}$ \\ Mohammad Sadraeian ${ }^{3}$ \\ Mohamad Montazeri ${ }^{4}$ \\ Esmaeil Biazar ${ }^{5}$ \\ 'Stem Cell Preparation Unit, Eye \\ Research Center, Farabi Eye Hospital, \\ Tehran University of Medical \\ Sciences; ${ }^{2}$ Department of Biomaterial \\ Engineering, Faculty of Biomedical \\ Engineering, Science and Research \\ Branch - Islamic Azad University; \\ ${ }^{3}$ Young Researchers Club, Islamic \\ Azad University, North Tehran Branch, \\ Tehran; ${ }^{4}$ Faculty of Medical sciences, \\ Babol University of Medical Sciences, \\ Babol; ${ }^{5}$ Department of Chemistry, \\ Islamic Azad University, Tonekabon, \\ Iran.
}

\begin{abstract}
Surface modification of medical polymers is carried out to improve biocompatibility. In this study, conventional polyurethane was exposed to microwave plasma treatment with oxygen and argon gases for 30 seconds and 60 seconds. Attenuated total reflection Fourier transform infrared spectra investigations of irradiated samples indicated the presence of functional groups. Atomic force microscope images of samples irradiated with inert and active gases indicated the nanometric topography of the sample surfaces. Samples irradiated by oxygen plasma indicated high roughness compared with those irradiated by inert plasma for the different lengths of time. In addition, surface roughness increased with time, which can be due to a reduction of contact angle of samples irradiated by oxygen plasma. Contact angle analysis indicated a reduction in samples irradiated with both types of plasma. However, samples irradiated with oxygen plasma indicated lower contact angle compared with those irradiated by argon plasma. Cellular investigations with unrestricted somatic stem cells showed better adhesion, cell growth, and proliferation among samples radiated by oxygen plasma for longer than for normal samples.
\end{abstract}

Keywords: surface topography, polyurethane, plasma treatment, cellular investigation

\section{Introduction}

Control of surface properties is very important for high-performance adhesion. Biomaterial wettability is an important factor in the surface modification of materials. Surface modification of hydrophobic polymer surfaces can be achieved by wet (acid, alkali), dry (plasma), or radiation treatments (ultraviolet radiation and laser). ${ }^{1-3}$ Nonthermal and low-pressure plasma have been used in a series of surface treatment applications. The majority of plasma-assisted technologies are based on low-pressure processes. ${ }^{4}$ The treatment of polymeric materials with plasma is a frequently used technique to accomplish surface modifications, chemical composition, and surface topography. Moreover, microwave discharge is routinely employed in the processing of materials to deposit films as well as coatings..$^{5-7}$ Physical surface modification and its effects on wettability are an interesting field for surface engineers. It should be noted that there has been a great deal of scientific research on molecularly smooth or modeled 'simply rough' surfaces ${ }^{8}$ but little work has been done on wettability and spreading phenomena of real engineering surfaces. ${ }^{9}$ From a practical point of view, a simple methodology is needed to account for the heterogeneous rough surface influence on wetting and contact angle measurements. The first attempt at establishing a methodology was made by Wenzel. ${ }^{10}$ His simple model was based on the assumption that rough surfaces extend the solid-liquid interface area in comparison with a projected smooth surface.
Correspondence: Esmaeil Biazar Islamic Azad University - Tonekabon Branch, Mazandaran, Iran

Tel +98 I9242744I5

Fax +98 I9242744 II

Email e.biazar@tonekaboniau.ac.ir 
Plasma treatment is generally used for the surface modification of polymers because the processes involved are solvent free and dry, the consumption of chemicals is extremely low, and the need for sterilization of the products is eliminated. Moreover, these processes are precisely controllable. The surface can be treated homogeneously, and the surface chemistry can be tailored for the required end use. ${ }^{11}$ The plasma method includes energetic neutrals, ions, and electrons, which act on a surface under treatment to change its physicochemical properties. The nature of the gas used and the energy of the ions are important parameters that can affect the properties of the polymer surface that is immersed in plasma. ${ }^{11}$

Polyurethanes are inherently resistant to cell growth and adhesion. When blood cells do not adhere, they do not accumulate and can cause undesired thrombi formation, thus making them hemocompatible. ${ }^{12}$ Another application for polyurethane is wound healing. ${ }^{13}$ In order to modify the surface chemistry of polyurethane and promote rapid tissue repair, various methods have been developed, such as plasma surface treatment. ${ }^{14}$

This study used unrestricted somatic stem cells (USSCs). USSCs were first isolated from the umbilical cord blood in 2003 by Jager et al. ${ }^{15}$ Their differentiation capacity for transplantation was evaluated. In 2004, Kogler et al ${ }^{16}$ also evaluated these cells for cytokine production. USSCs are pluripotent and are considered to be rare cell populations in umbilical cord blood. USSCs have a high potential to proliferate and differentiate, so they are considered valuable sources in cell therapy. USSCs are CD4-adherent and human leukocyte antigen class II-negative stem cells with a long telomerase. Moreover, these cells possess a unique cytokine profile and are associated with self-renewing factors. In spite of other cord blood-derived mesenchymal cells, which are differentiated only into osteoblasts, chondrocytes, adipocytes, ${ }^{17}$ and neurons, ${ }^{16}$ USSCs have the potential to be differentiated into osteoblasts, chondrocytes, blood cells, neurons, hepatocytes, and heart tissue under ex vivo conditions. ${ }^{16}$ The cells express different factors, including adherent cells, growth factors, and various cytokines, such as stem cell factor, vascular endothelial cell growth factor, granulocyte macrophage colony stimulating factor, macrophage colony stimulating factor, transforming growth factor-1 $\beta$, interleukin (IL)-6, granulocyte colony stimulating factor, leukemia inhibitory factor, Flt3 ligand, thrombopoietin, hematopoietic growth factor, stromal cell-derived factor-1 $\alpha$, IL-15, IL-12, IL-8, and IL-1 $\beta .{ }^{17}$

In this study, we demonstrate the effect of plasma on the surface property of polyurethane with argon (inert) and oxygen (reactive) and the influence of surface roughness on wetting properties.

\section{Materials and methods}

A solution of $250 \mathrm{~mL}$ dimethylformamide (Sigma-Aldrich Co., St Louis, MO, USA) was poured into a $50 \mathrm{~mL}$ tube, then $2.5 \mathrm{~g}$ of polyurethane (Bayer) was added to the solution and stirred well for 12 hours. The homogenous solution was poured into a Petri dish and kept at $25^{\circ} \mathrm{C}$ for a few days. In this experiment, we used a microwave plasma source to modify the surface of polyurethane samples. The microwave plasma has a significant advantage over other techniques like radiofrequency glow discharge and is frequently used in polymer surface modifications. ${ }^{12}$ Microwave sources can be operated at low pressures $\left(10^{-3}\right.$ to $\left.10^{-1} \mathrm{mbar}\right)$, which reduces the risk of gas phase contamination during processing. Moreover, the plasma properties can be controlled conveniently by adjusting the microwave power; hence, surface modification of the polymer becomes important.

In this paper, we demonstrate the effect of microwave plasma on the surface properties of polystyrene with argon (inert) and oxygen (active) for different lengths of time. Culture dishes (orange) with a diameter of $60 \mathrm{~mm}$, size $1 \mathrm{~cm} \times 1 \mathrm{~cm}$, were placed in ethanol solution for 24 hours for pollution elimination. Samples were placed in a plasma chamber and exposed to oxygen and argon gases for 30 seconds, 1 minute, and 3 minutes. The samples irradiated for the different lengths of time were investigated by structural analysis and microscopic investigations. Treatment with microwave-induced plasma with surface wave was at a power level of $100 \mathrm{~W}$. The experimental setup is shown in Figure 1.

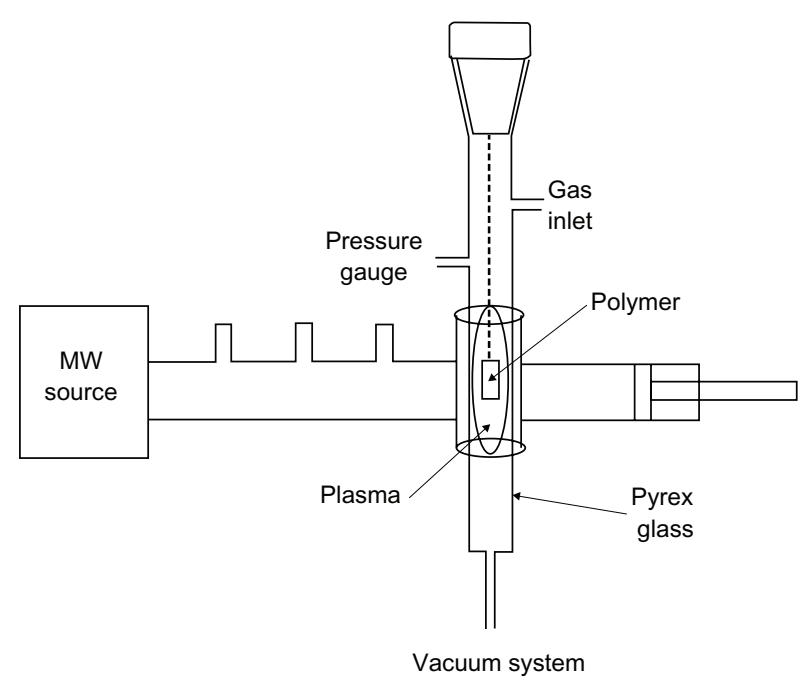

Figure I Experimental setup of the microwave plasma instrument. 


\section{Attenuated total reflection Fourier transform infrared analysis}

For surface identification of modified samples, the samples were studied before and after surface modification by an infrared spectrometer device (Thermo Nicolet Nexus 870). For this study, samples were cleaned before being used. The test was carried out based on the frequency absorption of covalent bands.

\section{Atomic force microscope analysis}

An atomic force microscope (Nanosurf easyScan) was used for studying the surface properties. The surface roughness that resulted from plasma treatment was observed by the microscope.

\section{Contact angle analysis}

The sample surfaces' static contact angles were investigated by a contact angle measuring device (Krüss G10; Krüss, Matthews, NC, USA) following the sessile drop method. The contact angle formed was defined as the angle between the solid/liquid and liquid/vapor join surface.

\section{Cellular analysis}

\section{Culture and isolation of USSCs from fresh} umbilical cord blood

After obtaining consent from mothers, blood from their umbilical cords was taken from the cord vein. Only $40 \%$ of the cord blood samples contained USSCs. The mean age of donors was 28 years. After collecting the samples, red blood cells were lysed using ammonium chloride, and the isolation procedure was continued with Ficoll. The samples were rinsed twice with sterile phosphate buffered saline (PBS) (pH 7.4). After centrifuging, the resultant cells were placed in low-glucose Dulbecco's modified Eagle's medium (DMEM), which had been enriched with $100 \mathrm{~nm}$ dexamethasone, $10 \%$ fetal bovine serum (FBS), penicillin, and streptomycin antibiotics. The first medium exchange process was carried out every 24 hours, then every 4 days. When $80 \%$ of the flask surface area was covered by cells, they were passaged using $0.25 \%$ trypsin and ethylenediaminetetraacetic acid (EDTA). USSCs were regularly expanded on the culture medium. A temperature of $37^{\circ} \mathrm{C}$ and $5 \%$ carbon dioxide were required for growth. The USSCs were first trypsinized and counted. The tubes, containing $10^{5}-10^{6}$ cells, were incubated on a rocker rotator for 10-16 hours and centrifuged at $1000 \mathrm{rpm}$ for 6 minutes, and 3\% human serum was added to the cell deposition thereafter. The resultant mixture remained at room temperature for 30 minutes. The cells were again centrifuged as previously, and PBS was added to the cell deposition.
The cell mixture was passed through a nylon mesh, and $100 \mu \mathrm{L}$ of cells was added to each tube with the following antibodies: anti-CD90, anti-CD105, anti-CD166, anti-CD45, anti-CD73, and anti-CD34. The tubes were kept at $4^{\circ} \mathrm{C}$ out of the light for 45 minutes. After washing, the cells were fixed in $100 \mu \mathrm{L}$ of $1 \%$ paraformaldehyde. Finally, flow cytometric analysis was carried out. Before and after coculture of mouse embryonic stem cells with USSCs, karyotype analysis was performed on both cell types. The first and last passages were preferably chosen for karyotype analysis. The cells were first placed in an incubator with $0.1 \mu \mathrm{g} / \mathrm{mL}$ colcemid for 3-4 hours. Next, they were trypsinized and $0.075 \mathrm{M}$ potassium chloride solution was added to them thereafter. The cells were incubated with $5 \%$ carbon dioxide at $37^{\circ} \mathrm{C}$ for 20 minutes. In the next stage, methanol and acetic acid in a 1:3 ratio were added to fix the samples. Finally, the cells scattered over the slide surface and chromosomes were subjected to karyotype analysis.

\section{Cell culture study on the polymer surface}

The powders and control (TCPS) samples were well cleaned and sterilized by the autoclave method. Individual samples were placed in Petri dishes using a sterilized pincer. The USSC suspension was transferred to a flask ( $25 \mathrm{cc}$ ) containing $5 \mathrm{~mL}$ DMEM, $2 \mathrm{~mm}$ l-glutamine, penicillin $(100 \mathrm{lu} / \mathrm{mL})$, streptavidin $(100 \mathrm{~L} / \mathrm{mL})$, and FBS $10 \%$. The suspension was then placed in an incubator $\left(5 \%\right.$ carbon dioxide, $\left.37^{\circ} \mathrm{C}\right)$. The fibroblast cells were proliferated in the flask and washed using FBS/EDTA. Then, the trypsin enzyme/EDTA was added to the flask $\left(4^{\circ} \mathrm{C}\right)$, and the flask was incubated for 2 minutes. The culture media (FBS/DMEM) was added to the flask and the cells were gently pipetted. The cell suspension was transferred to a falcon tube $(15 \mathrm{~mL})$ and centrifuged (1410 rpm) for 5 minutes. The solution was removed and the precipitation was transferred to a new flask $(75 \mathrm{cc})$ for reculturing. Pieces of cell culture $(1 \times 1 \mathrm{~cm})$ from the Petri dish (control) and the main sample were placed individually in one of the Petri dish wells using a sterilized pincer. A total of 100,000 cells/well seeded into a 24-well culture plate were removed by pipette and poured on to the control and the main samples. Then, all of the samples were placed in a Memmert incubator at $37^{\circ} \mathrm{C}$ for 48 hours and studied using a Ceti microscope (Wolf Laboratories, UK). Cellular viability was determined by 3-(4,5-dimethylthiazol-2-yl)-2, 5-diphenyltetrazolium bromide (MTT) assay.

The MTT tetrazolium compound is reduced by living cells into a colored formazan product that is soluble in a tissue culture medium. The quantity of formazan product 

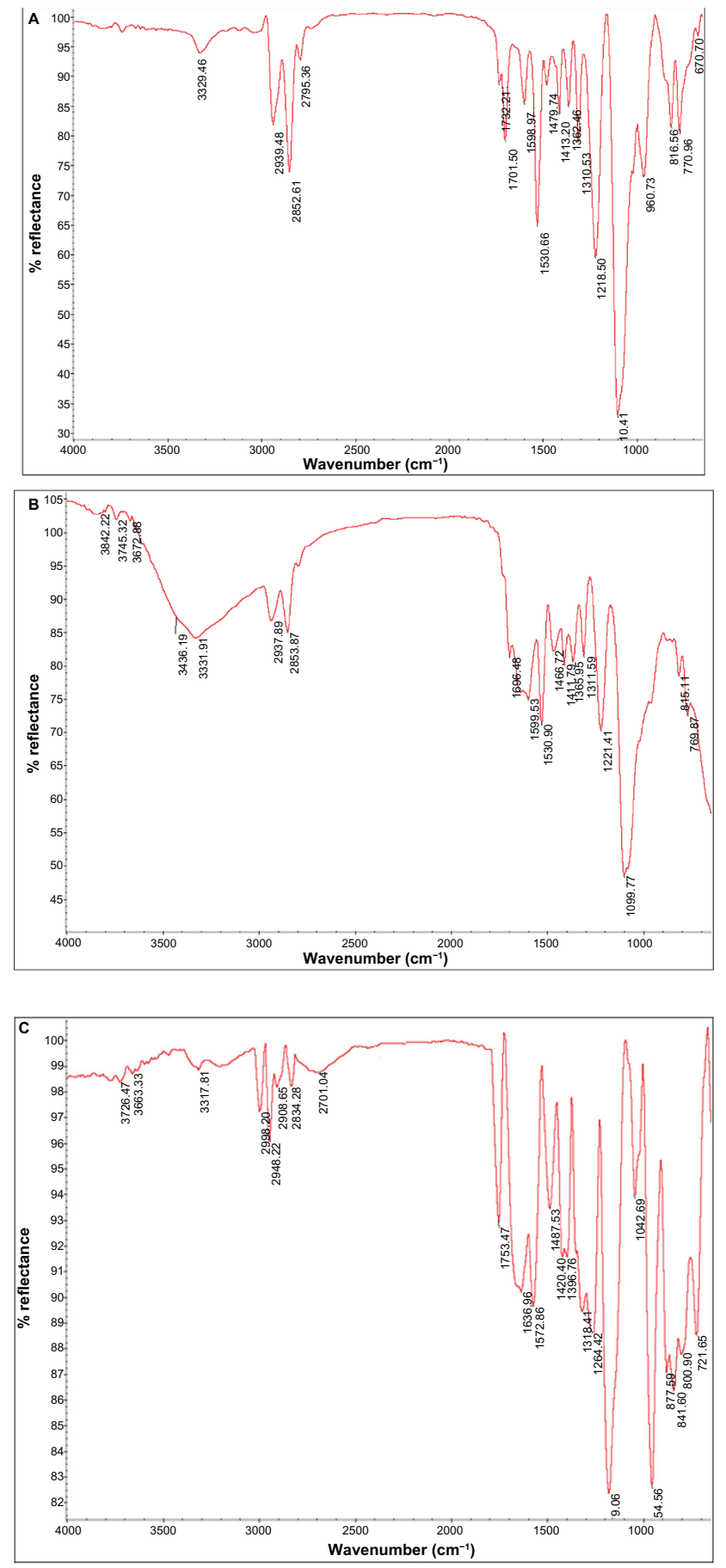

Figure 2 Spectra of attenuated total reflection Fourier transform infrared of normal polyurethane (A), polyurethane modified by oxygen plasma (B), and polyurethane modified by argon plasma $(\mathbf{C})$.

is directly proportional to the number of viable cells in the culture. The assays were performed by adding $1 \mathrm{~mL}$ of MTT solution (Sigma-Aldrich) and $9 \mathrm{~mL}$ fresh medium to each well after aspirating the spent medium and incubating at $37^{\circ} \mathrm{C}$ for 4 hours with protection from light. Colorimetric measurement of formazan dye was performed at a wavelength of $606 \mathrm{~nm}$ using a Rayto Microplate Reader.

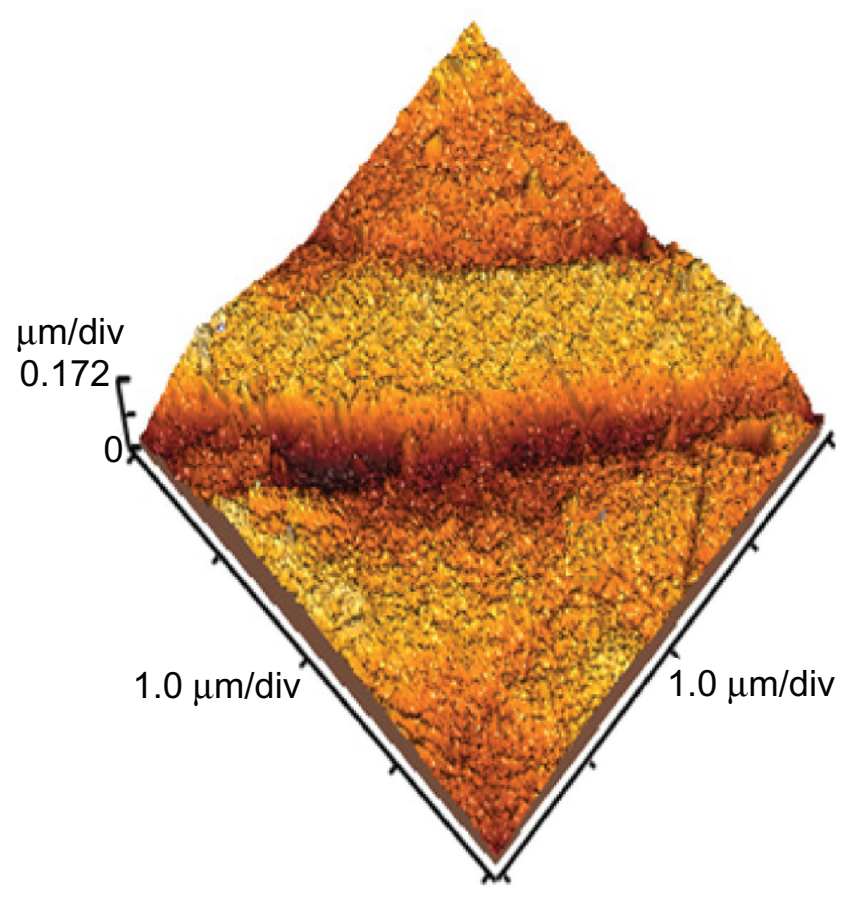

Figure 3 Topography of normal polyurethane.

\section{Results}

\section{Attenuated total reflection Fourier} transform infrared analysis

Attenuated total reflection Fourier transform infrared (ATR-FTIR) spectra results of normal and modified polyurethane samples treated with plasma radiation (oxygen and argon gases) for different lengths of time are shown in Figure 2. ATR-FTIR spectra of polyurethane irradiated with argon plasma is shown in Figure 2C. There was no significant difference between normal (A) and samples irradiated with argon plasma. However, a significant difference was observed in $3400-3600 \mathrm{~cm}^{-1}$ that could be related to the $\mathrm{OH}$ group and proved the effect of surface treatment compared with the normal sample. ATR-FTIR spectra of polyurethane irradiated with oxygen plasma are shown in Figure 2B. The spectra were observed in $1750 \mathrm{~cm}^{-1}$ that could be related to the $\mathrm{C}=\mathrm{O}$ group and successfully showed surface modification with oxygen plasma. The tension peak of $1000-1300 \mathrm{~cm}^{-1}$ could be related to the $\mathrm{C}-\mathrm{O}$ group and a peak of $3000 \mathrm{~cm}^{-1}$ could be related to the $\mathrm{CH} 3$ group. Moreover, the tension peak observed in $3400-3800 \mathrm{~cm}^{-1}$ could be related to the $\mathrm{OH}$ and $\mathrm{OOH}$ groups, which proved the effect of surface treatment on the samples.

\section{Atomic force microscope analysis}

The surface topology of normal and polyurethane samples irradiated for different lengths of time and exposure 
A
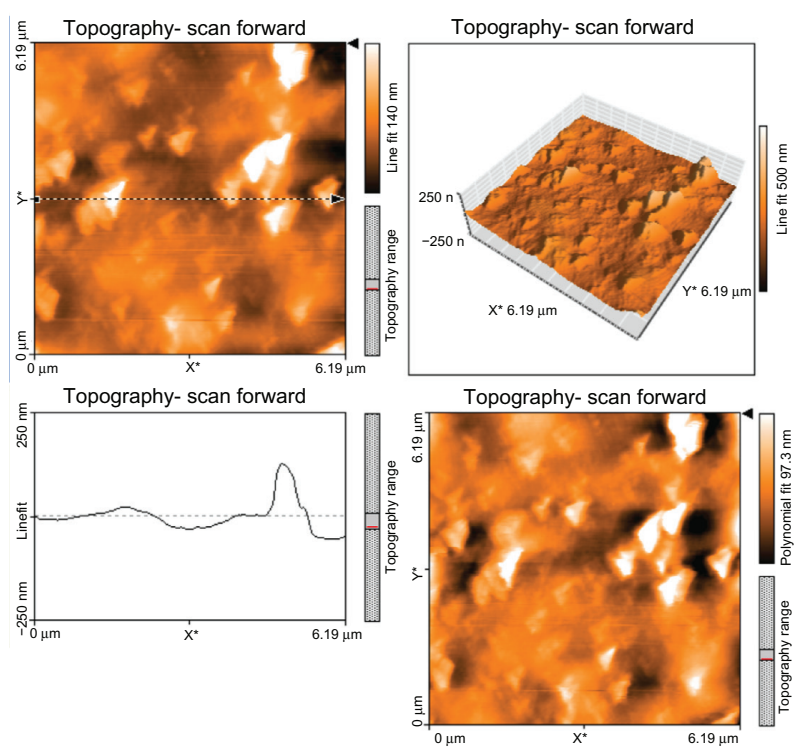
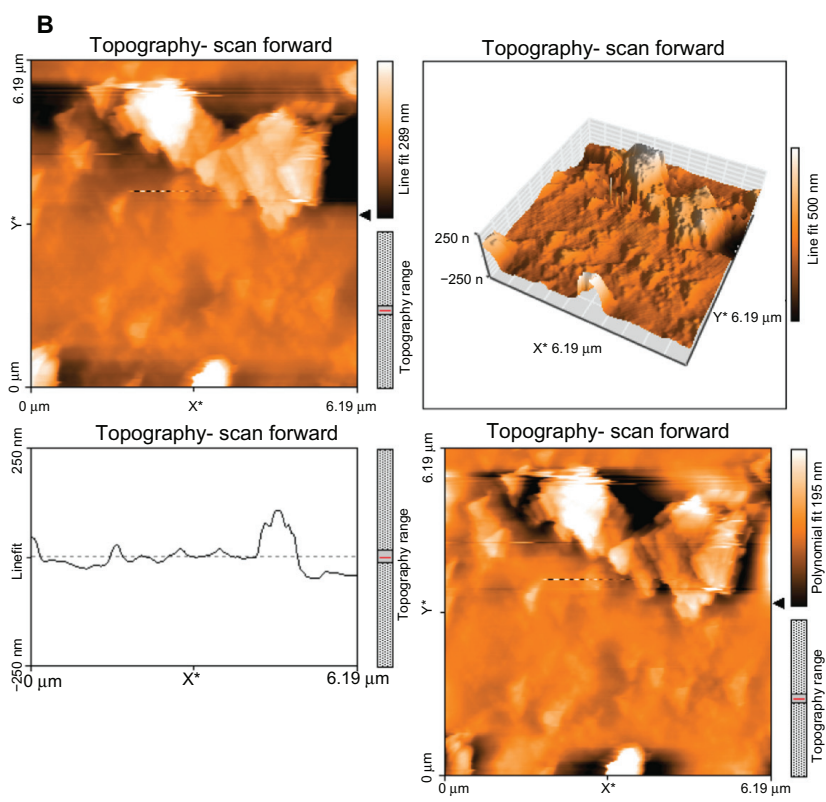

Figure 4 Topography of polyurethane modified by argon plasma for 30 seconds (A) and 60 seconds (B).

(active and inert gases) was investigated using atomic force microscopy. Three-dimensional topography of normal samples is shown in Figure 3. In the figure, smooth surface with little roughness can be observed. The roughness could be related to scratches resulting from the cleaning process for samples.

Figure 4 shows the topography of the polystyrene modified with argon plasma for 30 seconds (A) and 60 seconds (B). A difference was observed between the topography of samples irradiated with argon plasma at different times with those of normal samples. Surface roughness increased with time, but not many differences were observed in the surface topology.

Figure 5 shows the topography of the polyurethane modified with oxygen plasma for 30 seconds (A) and 60 seconds (B). The topography of samples irradiated with oxygen plasma for different lengths of time was different compared with that of normal samples and those modified with argon plasma. Surface roughness was increased with time of exposure to oxygen plasma. Many differences were observed in surface topology with an increase in exposure time.

A
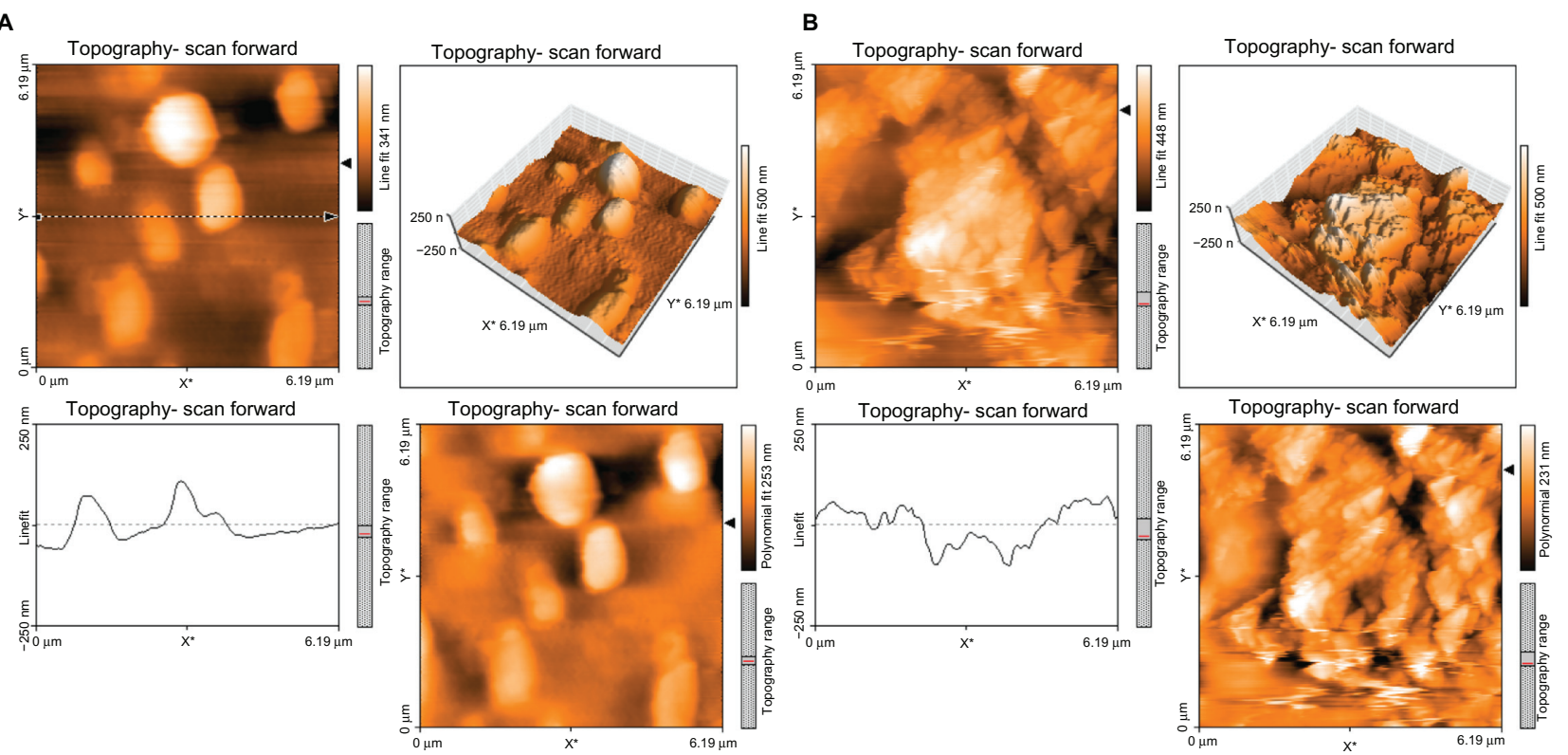

Figure $\mathbf{5}$ Topography of polyurethane modified by oxygen plasma for 30 seconds (A) and 60 seconds (B). 
Table I Contact angles of normal and irradiated samples (average)

\begin{tabular}{lll}
\hline Sample & $\begin{array}{l}\theta \text { (degrees) } \\
\text { (treated by } \\
\text { argon plasma) }\end{array}$ & $\begin{array}{l}\theta \text { (degrees) } \\
\text { (treated by } \\
\text { oxygen plasma) }\end{array}$ \\
\hline Normal & 78.1 & 78.1 \\
30 seconds & 44.6 & 17.2 \\
60 seconds & 42.6 & 13.7 \\
\hline
\end{tabular}

\section{Contact angle analysis}

Table 1 shows the angles obtained for normal samples and those modified with oxygen and argon plasma for different lengths of time. The results show that samples modified with both gases have a reduced contact angle. The sample modified with oxygen plasma showed a higher level of contact angle reduction compared with the sample modified with argon plasma, which means that the sample modified with oxygen plasma has become hydrophilic compared with the normal sample.

\section{Cellular results}

USSCs were isolated from the cord blood and cultured. The cells were continuously cultured during 50 passages. USSCs have a high proliferation capacity, as they need to repeat passages. The proliferation and morphology of these cells were similar to each other before and after freezing. No indication of viral or mycoplasmal infection was observed during the different stages. USSCs are morphologically adherent and spindle-shaped cells with a size of 20-25 $\mu \mathrm{m}$. After three passages, flow cytometric analysis was performed on USSCs in order to express stem cell markers.

Before beginning the experiments, karyotype analysis was performed on USSCs of passage 2. The analysis showed that they depicted a normal 44,XX karyotype. After 48 passages, these cells were subjected to karyotype analysis once again, and it was indicated that they have a normal chromosome karyotype of 44,XX.

\section{Cellular study}

Table 2 shows the MTT assay for TCPS (control), normal polyurethane film, and polyurethane films irradiated with plasma (oxygen and argon gases) for different lengths of time (30 seconds and 60 seconds). The results show high viability

Table 2 MTT analysis of the samples

\begin{tabular}{lllll}
\hline Sample & $\begin{array}{l}\lambda \\
(\mathbf{n m})\end{array}$ & $\begin{array}{l}\text { Cell viability } \\
\text { (treated by argon } \\
\text { plasma) }\end{array}$ & $\begin{array}{l}\lambda \\
(\mathbf{n m})\end{array}$ & $\begin{array}{l}\text { Cell viability } \\
\text { (treated by argon } \\
\text { plasma) }\end{array}$ \\
\hline Control & 606 & 100 & 606 & 100 \\
Normal & 335 & 55 & 335 & 55 \\
30 seconds & 352 & 58 & 427 & 70 \\
60 seconds & 457 & 75 & 910 & 150 \\
\hline
\end{tabular}
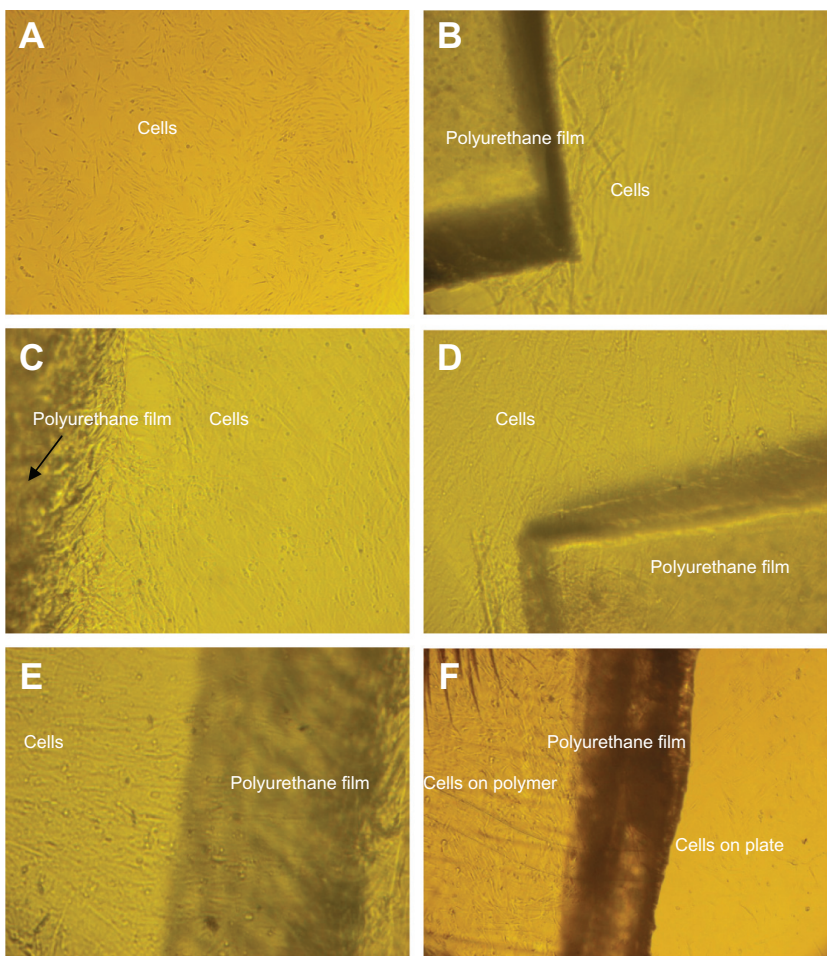

Figure 6 Unrestricted somatic stem cell culture on the (A) control (TCPS) surface, (B) normal polyurethane (PU), (C) PU modified by argon plasma (30 seconds), (D) PU modified by argon plasma (60 seconds), (E) PU modified by oxygen plasma (30 seconds), and (F) PU modified by oxygen plasma (60 seconds).

for samples irradiated with plasma for different lengths of time as well as different gases (58\% [30 seconds, argon plasma], 75\% [60 seconds, argon plasma], 70\% [30 seconds, oxygen plasma], and 150\% [60 seconds, oxygen plasma]), but films irradiated with plasma and both gases for longer showed better viability. Samples irradiated with plasma for 60 seconds caused proliferation of more cells. Figure 6 shows cell culture images on the normal and irradiated films as well as control samples. Figures $6 \mathrm{~A}$ and $6 \mathrm{~B}$ show normal polyurethane film and the control sample. Figures $6 \mathrm{C}$ and 6D show films radiated with argon plasma for 30 seconds and 60 seconds. Figures $6 \mathrm{E}$ and $6 \mathrm{~F}$ show films irradiated with oxygen plasma for 30 seconds and 60 seconds. Cellular images show growth for irradiated films, especially those irradiated with active gases for longer.

\section{Conclusion}

In this study, surface modification and topology of normal polyurethane and polyurethane irradiated with oxygen and argon plasma for different lengths of time were investigated. ATR-FTIR analysis of samples modified by two gases proved the existence of functional groups such as $\mathrm{C}=\mathrm{O}, \mathrm{CO}, \mathrm{OH}$, and $\mathrm{OOH}$ for oxygen plasma treatment and $\mathrm{OH}$ for argon gas. $\mathrm{AFM}$ images showed more surface roughness of samples modified 
with oxygen plasma in comparison with normal samples and those modified with argon plasma. Contact angle analysis showed further contact angle reduction for samples modified with oxygen plasma in comparison with samples modified with argon plasma. These differences could be related to physical modification or the roughness of samples modified with oxygen plasma in comparison with samples modified with argon plasma that were shown in the microscopic images. Cellular investigations with USSCs showed better adhesion, growth, and viability of films irradiated with both plasma types, especially oxygen plasma, than normal films. Therefore, the results show that roughness and cellular adhesion increase with plasma treatment $(\mathrm{OOH}$ and $\mathrm{OH})$. These irradiated films could be used as substrates for cellular culture.

\section{Disclosure}

The authors report no conflicts of interest in this work.

\section{References}

1. Lu HW, Lu QH, Chen WT, et al. Cell culturing on nanogrooved polystyrene Petri dish induced by ultraviolet laser irradiation. Materials Letters. 2004;58:29-32.

2. Roucoules G, Mathia T, Lanteri P. Hydrophobic mechano chemical treatment of metallic surfaces. Wettability measurements as means of assessing homogeneity. Adv in Colloids and Interf Sciences. 2002; 97:177-201.

3. Hay KM, Dragila MI, Liburdy J. Theoretical model for the wetting of a rough surface. J of Colloid Interf Science. 2008;325:472-477.

4. Kogelschatz U. Dielectric-barrier discharges: their history, discharge physics and industrial applications. Plasma Chem Plasma Process. $2003 ; 23: 1-46$.
5. Kuzmichev Al. Ion plasma sources based on a microwave oven. Instrum Exp Tech. 1994;37:648-653.

6. Asmussen V. Electron cyclotron resonance microwave discharge for etching and thin film deposition. J Vac Sci Techno. 1989;7:883-889.

7. Takahashi C, Jin Y, Nishimura K, Matsuo S. Anisotropic etching of Si and WSiN using ECR plasma of SF6-CF4 gas mixture. Jpn J Appl Phys. 2000;39:3672-3676.

8. Prabhu KN, Fernandes P, Kumar G. Effect of surface roughness on wetting characteristics of vegetable oils. Materials and Design. 2009;30:297-305.

9. Kubiak KJ, Mathia TG, Wilson MCT. Methodology for metrology of wettability versus roughness of engineering surfaces. Proceedings of the 14th Congrès International De Métrologie; June 22-25, 2009; Paris, France.

10. Wenzel RN. Resistance of solid surfaces to wetting by water. Ind Eng Chem. 1936;28:988-994.

11. Chan CM, Ko TM, Hiraoka H. Polymer surface modification by plasmas and photons. Surface Science and Reports. 1996;24:1.

12. Colligon JS, Dekker A, Curry A, Kirkpatrick CJ. Oxygen plasma modification of polyurethane membranes. J Mater Sci Mat Med. 1996;7:119.

13. Zhang JY, Beckman EJ, Piesco NP, et al. A new peptide-based urethane polymer: synthesis, biodegradation, support cell growth in vitro. Biomaterials. 2000;21:1247.

14. Kayirhan N, Denizli A, Hasirci N, et al. Adsorption of blood proteins on glow-discharge-modified polyurethane membranes. J App Poly Sci. 2001;81:1322.

15. Jager M, Sager M, Knipper A, et al. In vitro und in vivo Knochenregenerierung durch mesenchymale sstammzellen aus dem nabelschnurblut. Orthoped. 2004;33:1361-1372.

16. Kogler G, Sensken S, Airey JA, et al. A new human somatic stem cell from placental cord blood with intrinsic pluripotent differentiation potential. J Exp Med. 2004;200:123-135.

17. Kogler G, Radke TF, Lefort A, et al. Cytokine production and hematopoiesis supporting activity of cord blood-derived unrestricted somatic stem cells. Exp Hematol. 2005;33:573-583.
International Journal of Nanomedicine

\section{Publish your work in this journal}

The International Journal of Nanomedicine is an international, peerreviewed journal focusing on the application of nanotechnology in diagnostics, therapeutics, and drug delivery systems throughout the biomedical field. This journal is indexed on PubMed Central, MedLine, CAS, SciSearch $₫$, Current Contents ${ }^{\circledR} /$ Clinical Medicine,

\section{Dovepress}

Journal Citation Reports/Science Edition, EMBase, Scopus and the Elsevier Bibliographic databases. The manuscript management system is completely online and includes a very quick and fair peer-review system, which is all easy to use. Visit http://www.dovepress.com/ testimonials.php to read real quotes from published authors. 